\title{
1 Genome-wide identification of novel sRNAs in Streptococcus mutans
}

2 Madeline C Krieger ${ }^{1,2}$, Justin Merritt ${ }^{2}$, Rahul Raghavan ${ }^{1,3}$

$4 \quad{ }^{1}$ Department of Biology, Portland State University, Portland, OR, USA.

$5 \quad{ }^{2}$ Department of Restorative Dentistry, School of Dentistry, Oregon Health and Science

6 University, Portland, OR, USA.

$7 \quad{ }^{3}$ Department of Molecular Microbiology and Immunology, The University of Texas at San

8 Antonio, San Antonio, TX, USA.

10 Author for correspondence:

11 Rahul Raghavan | Email: rahul.raghavan@utsa.edu

13 Key words: sRNA, Streptococcus mutans, 6S RNA, sugar-phosphate stress, sorbitol,

14 transcriptome

15

16

17

18 


\section{ABSTRACT}

25 Streptococcus mutans is a major pathobiont involved in the development of dental caries. Its

26 ability to utilize numerous sugars and to effectively respond to environmental stress promotes $S$.

27 mutans proliferation in oral biofilms. Because of their quick action and low energetic cost, non-

28 coding small RNAs (sRNAs) represent an ideal mode of gene regulation in stress response

29 networks, yet their roles in oral pathogens have remained largely unexplored. We identified 15

30 novel sRNAs in $S$. mutans and show that they respond to four stress-inducing conditions

31 commonly encountered by the pathogen in human mouth: sugar-phosphate stress, hydrogen

32 peroxide exposure, high temperature, and low $\mathrm{pH}$. To better understand the role of sRNAs in $S$.

33 mutans, we further explored the function of the novel sRNA, SmsR4. Our data demonstrate that

34 SmsR4 regulates the EIIA component of the sorbitol phosphotransferase system, which

35 transports and phosphorylates the sugar alcohol sorbitol. The fine-tuning of EIIA availability by

36 SmsR4 likely promotes $S$. mutans growth while using sorbitol as the main carbon source. Our

37 work lays a foundation for understanding the role of sRNAs in regulating gene expression in

38 stress response networks in $S$. mutans and highlights the importance of the underexplored

39 phenomenon of posttranscriptional gene regulation in oral bacteria. 


\section{IMPORTANCE}

42 Small RNAs (sRNAs) are important gene regulators in bacteria, but the identities and functions

43 of sRNAs in Streptococcus mutans, the principal bacterium involved in the formation of dental

44 caries, are unknown. In this study, we identified 15 putative sRNAs in S. mutans and show that

45 they respond to four common stress-inducing conditions present in human mouth: sugar-

46 phosphate stress, hydrogen peroxide exposure, high temperature, and low $\mathrm{pH}$. We further show

47 that the novel sRNA SmsR4 likely modulates sorbitol transport into the cell by regulating

48 SMU_313 mRNA, which encodes the EIIA subunit of the sorbitol phosphotransferase system.

49 Gaining a better understanding of sRNA-based gene regulation may provide new opportunities to

50 develop specific inhibitors of S. mutans growth, thereby improving oral health. 


\section{INTRODUCTION}

53 The gram-positive oral pathogen Streptococcus mutans plays a principal role in the formation of

54 dental caries and is often considered to be the primary causative agent of the disease (1-3).

55 Central to $S$. mutans cariogenicity is its ability to ferment a wide variety of sugars, resulting in

56 the formation of acidic microenvironments that drive the decline of commensal species and the

57 proliferation of aciduric bacteria (4). One factor that allows $S$. mutans to metabolize a variety of

58 carbon sources is the presence of 14 phosphotransferase systems (PTSs) $(5,6)$. PTSs act by

59 transporting carbohydrates across the cell membrane and immediately phosphorylating them for

60 intracellular retention and entry into glycolysis (7). While glucose is the preferred carbon source

61 for S. mutans, other PTSs, including the sorbitol (glucitol) PTS, are inducible in its absence.

62 Sorbitol is a sugar-alcohol found naturally in many fruits and is a popular low-calorie anti-

63 cariogenic sweetener $(7,8)$. The anticariogenic action of sorbitol is due to the relatively low

64 amounts of acid produced during sorbitol fermentation by S. mutans compared to that of glucose

65 or sucrose metabolism $(8,9)$.

The success of $S$. mutans in the oral cavity is enhanced not only by proficient sugar

67 utilization but also by its ability to quickly respond to rapidly changing environmental conditions

68 and multiple stressors (10). Small RNAs (sRNAs) are non-coding transcripts that typically bind

69 to their target mRNAs to regulate gene expression (11). Due to their low energetic cost, fast

70 action, and capacity for co-degradation with mRNA targets, sRNAs are an ideal mode of

71 posttranscriptional control when a bacterium is experiencing environmental stress (12).

72 Surprisingly little is known about sRNA-based regulation in S. mutans and there have been no

73 functional analyses of sRNA utility in S. mutans to date. In this study, we identified 15 putative 
74 sRNAs in S. mutans that respond to multiple stress conditions and describe a novel sRNA that

75 promotes bacterial growth in the presence of sorbitol.

\section{RESULTS}

\section{Identification and validation of novel sRNAs}

79 We used an RNA-seq-based approach that we developed previously (13-15) to identify 15 novel

80 sRNAs — named SmsR for "S. mutans small RNA" — expressed in S. mutans during

81 exponential (OD 600 0.5-0.6) growth in Brain Heart Infusion (BHI) broth (Figure 1). Nine of the novel sRNAs overlapped with candidates predicted by a previous genome-wide scan and a

83 search against the Rfam database identified three of the sRNAs as RNase P, 6S RNA, and

84 tmRNA $(16,17)$ (Table 1). All candidate sRNAs have putative -10 promoter sites, and 10 have

85 predicted rho-independent terminators at their $3^{\prime}$ ends (Table 2), indicating these as authentic

86 sRNAs. We further verified all 15 putative sRNA transcripts using Northern blot (Figure 1).

87 Interestingly, in a few cases, higher molecular weight bands in addition to the sRNAs were

88 observed, presumably because the sRNAs were cleaved from longer transcripts, as observed in 89 other bacteria (18-23).

\section{$91 \quad$ sRNAs respond to environmental stress}

92 We evaluated the expression of the 15 novel sRNAs following $S$. mutans exposure to four stress-

93 inducing conditions relevant to the human oral cavity: sugar-phosphate stress, hydrogen peroxide

$94\left(\mathrm{H}_{2} \mathrm{O}_{2}\right)$, high temperature, and low $\mathrm{pH}$ (Table 3). All sRNAs showed patterns of differential

95 expression in at least one of these conditions, suggesting likely roles in stress tolerance networks

96 (Figure 2). Acid and sugar-phosphate stress induced differential expression of 12 sRNAs, while 
97 eight sRNAs were affected by heat stress and four responded to oxidative stress (Figure 2).

98 Upregulation of sRNA expression was more common than downregulation across all conditions

99 except for heat stress.

100

101 SmsR14 and SmsR4 are unrelated sRNAs

102 6S RNA, a global regulator of transcription, is widely conserved among bacteria (24-26). Two

103 copies of 6S RNA are present in Bacillus subtilis, a model gram-positive bacterium: one in the

104 intergenic region between genes for azoreductase and RecQ helicase, and the other between two

105 tRNA-associated genes (Figure 3) (27). The prevalence of 6S RNA in Streptococcus has not

106 been examined previously. SmsR14, one of the newly-discovered sRNAs, is a 6S homolog and is

107 located between $\operatorname{rar} A$ and tRNA-Lys genes in $S$. mutans (Figure 3). A covariance modeling

108 (cm)-based search for 6S homologs in other Streptococcus species revealed only one copy of the

109 sRNA in all genomes we analyzed (Figure 4). Interestingly, another novel sRNA (SmsR4)

110 occupies the genomic location at which 6S RNA is present in Escherichia coli, i.e., upstream of

111 the gene encoding 5-formyltetrahydrofolate cyclo-ligase (5-FTC) (Figure 3) $(24,26,28)$.

112 SmsR4, however, is much shorter than 6S (110 nt vs $194 \mathrm{nt})$, has a predicted secondary structure

113 that is distinct from that of 6S, and is encoded on the opposite strand as 5-FTC gene (Figure 3).

114 These differences suggest that SmsR4 is unrelated to 6S RNA and could have distinct functions

115 in S. mutans.

117 SmsR4 arose in the Pyogenes-Equinus-Mutans clade of Streptococcus

118 The genus Streptococcus could broadly be classified into two clades: Mitis-Suis and Pyogenes-

119 Equinus-Mutans (29). Our cm-based search identified SmsR4 homologs only in the Pyogenes- 
120 Equinus-Mutans clade (Figure 4). Further, an evolutionary reconstruction showed that SmsR4

121 arose at the root of this clade but was later lost in the common ancestor of Sobrinus, Salivarus,

122 Halotolerans and Porci subclades. While the rest of the Pyogenes subclade members contain

123 SmsR4, it is absent in Streptococcus equi; similarly, in Entericus subclade, Streptococcus

124 marimmalium has lost the sRNA, but it is retained by Streptococcus entericus. Despite these

125 disparate cases of sRNA loss, the broad pattern of conservation of SmsR4 across a major clade

126 of Streptococcus suggests that the novel sRNA has important functions.

128 SmsR4 promotes $\boldsymbol{S}$. mutans growth in sorbitol-containing media

129 To identify the functions of SmsR4 in S. mutans, we first confirmed the 5' and 3' boundaries of

130 SmsR4 and generated an SmsR4-deletion (DEL) strain. We measured the growth of wild-type

131 (WT) and DEL strains using a phenotypic microarray (30). In this analysis, DEL had reduced

132 growth in comparison to WT in media containing sorbitol as the sole carbon source (Figure S1).

133 We verified this phenotype by measuring bacterial growth in BTR medium that contained either

$1340.5 \%$ glucose (BTR-G) or $0.5 \%$ sorbitol (BTR-S). In this assay DEL had weaker growth than

135 WT in BTR-S despite displaying a growth pattern identical to that of WT in BTR-G (Figure 5).

136 The growth defect of DEL in BTR-S was overcome by a complementation strain (COMP) in

137 which SmsR4 was expressed on the shuttle vector pDL278 $(31,32)$, indicating that the loss of

138 SmsR4 caused DEL's reduced growth. Probably because multiple copies of the SmsR4-carrying

139 plasmid were present in each cell, COMP grew considerably better than WT in BTR-S, again

140 denoting a role for the sRNA in promoting robust bacterial growth when using sorbitol as the

141 carbon source. 


\section{SmsR4 regulates the EIIA component of the sorbitol PTS}

144 In accordance with SmsR4's potential role in regulating bacterial growth on sorbitol, in silico

145 sRNA target prediction indicated that SmsR4 could bind to SMU_313, the gene encoding

146 enzyme IIA of the sorbitol PTS (Figure 6; Table S1). An SMU_313-deletion strain failed to

147 achieve meaningful growth in BTR-S but grew at comparable levels to WT in BTR-G (Figure

148 S2), demonstrating that SMU_313 is essential for growth on sorbitol but not glucose. We

149 confirmed the interaction between SmsR4 and SMU_313 mRNA with an RNA-RNA

150 electrophoretic mobility shift assay (EMSA), which showed that SmsR4 binds well to the 5'

151 UTR of SMU_313 mRNA (Figure 7A). The putative-SmsR4-binding site identified by in silico

152 analyses (Figure 6) is likely required for this interaction, as a mutation of the predicted SmsR4-

153 binding site in SMU_313 inhibited its in vitro interaction with SmsR4 (Figure 7B). Taken

154 together, our data indicate that SmsR4 modulates sorbitol import into the cell, likely by

155 antagonizing translation of SMU_313 mRNA, which encodes the EIIA subunit of the sorbitol

156 PTS.

\section{DISCUSSION}

159 sRNAs are critical for posttranscriptional gene regulation in bacteria, but their roles in the dental

160 pathogen $S$. mutans have remained largely unknown. Prior to our study, a mostly bioinformatics-

161 based analysis of gene expression in S. mutans grown with various carbon sources identified 243

162 sRNA candidates (17). In contrast, our approach combined genome-wide analysis with

163 experimental validation and uncovered 15 sRNAs expressed under a single growth condition

164 (BHI, OD 600 0.5-0.6) (Figure 1); hence, it is certainly possible that $S$. mutans transcribes

165 additional undetected sRNAs in growth conditions different from those examined here. We 
noticed several sRNAs that appeared to be processed from larger parent transcripts, e.g., SmsR3

168 documented; for example, OppZ and CarZ are produced by RNase E cleavage of the oppABCDF

169 and carAB mRNAs in Vibrio cholera, $\operatorname{ArgX}$ is produced from $\operatorname{argR}$ mRNA in Lactococcus

170 lactis, and RsaC is formed via RNase III digestion of mntACB mRNA in Staphylococcus aureus

171 (20,33-37). Alternatively, some of these sRNAs may be regulatory elements with multiple

172 products formed from premature transcriptional termination and transcriptional read-through

173 (38).

The genomic contexts of sRNAs likely have implications for their functions (Figure 1).

175 For instance, some of the sRNAs located in the 5' UTRs of downstream genes (e.g., SmsR5,

176 SmsR6, SmsSR8, SmsR16, SmsR20, SmsR22) could function as riboswitch-like elements (39),

177 or sRNAs that are transcribed divergently from downstream protein-coding genes (e.g., SmsR1,

178 SmsR3, SmsR19) could function as antisense sRNAs that regulate cis-encoded targets $(40,41)$.

179 A few sRNA genes in other bacteria have been shown to contain small open reading frames

180 (ORFs) that encode proteins (42). We searched the 15 sRNA sequences for ORFs and found that

181 SmsR12 potentially encodes a small protein (33 amino acids). Although we could not detect a

182 ribosome binding site upstream of the ORF and a BlastP search did not produce any hits in other

183 bacteria, further studies would be required to determine whether the ORF is indeed functional.

184 Because sRNAs identified in this study exhibited differential expression under stress and their

185 existence as discrete transcripts were validated via Northern blot, it is likely that they represent

186 bona fide sRNAs participating in regulatory networks. Aside from SmsR4, the functions of these

187 novel sRNAs are currently unknown, but preliminary in silico target predictions suggest that

188 many of them are involved in processes critical to adaptation and virulence. For instance, SmsR2 
and SmR22 are predicted to bind to PTS components, indicating that additional sRNAs may regulate sugar transport (Table S1), a process critical for S. mutans cariogenicity.

Among the 15 novel sRNAs, SmsR4 was intriguing because its genomic location is

192 similar to that of 6S RNA in many proteobacteria (24), and as observed for 6S, SmsR4 was

193 maximally expressed during the transition from exponential to stationary phase (Figure S3) (25).

194 In gammaproteobacteria, expression of $6 \mathrm{~S}$ is thought to be controlled by its linkage to the neighboring 5-FTC gene, which responds to nutrient limitation during the transition to stationary

196 phase (24). In a similar manner, SMU_320, the 5-FTC homolog in S. mutans, could influence the expression of SmsR4; however, unlike with 5-FTC and 6S in gram-negative bacteria, SMU_320

198 and SmsR4 are encoded on opposite DNA strands and hence are not co-transcribed. Instead, a

199 unique promoter likely initiates SmsR4 transcription (Table 2).

201 unsurprising to find an sRNA regulator of its sorbitol usage. While further work is required to

202 delineate the molecular details of its action, our results indicate that SmsR4 likely functions by

203 modulating translation of the EIIA component of the sorbitol PTS. When sugars are transported

204 through PTS systems, EIIA (e.g., SMU_313) participates in phosphorylation of the incoming

205 sugar molecule as it enters into the cytoplasm (43). If left unchecked, phosphorylated sugars can

206 accumulate in the cell and trigger sugar-phosphate stress (44). In E. coli and Salmonella enterica,

207 the sRNA SgrS plays a key role in restoring glycolytic balance during sugar-phosphate stress by

208 blocking the translation of mRNAs encoding the corresponding sugar-transporters $(45,46)$. In a

209 similar fashion, SmsR4 could be modulating sorbitol intake by regulating the expression of

210 SMU_313 $\left(\right.$ EIIA $\left.^{\text {sorb }}\right)$ to relieve S. mutans sugar-phosphate stress during the transition from

211 exponential to stationary phase growth in sorbitol-containing growth medium. Alternatively, 
212 modulation of SMU_313 expression by SmsR4 could impact alternative functions of EIIA. For

213 example, this protein has been shown to negatively impact glycerol metabolism in Klebsiella

214 pneumoniae and to reduce $S$. enterica virulence $(47,48)$. In conclusion, our in silico and

215 biochemical data both support a role for sRNAs as posttranscriptional regulators of sugar

216 transport through PTS systems. Further insights into these regulatory mechanisms may provide

217 new opportunities to develop specific inhibitors of $S$. mutans growth in the oral cavity.

219 MATERIALS AND METHODS

220 Bacterial strains and growth assays

221 Growth experiments were conducted by diluting overnight cultures of S. mutans UA159 in fresh

222 media. BTR broth base (1\% Bacto-Tryptone, $0.1 \%$ yeast extract, $\left.0.61 \% \mathrm{~K}_{2} \mathrm{HPO}_{4}, 0.2 \% \mathrm{KH}_{2} \mathrm{PO}_{4}\right)$

223 supplemented with either $0.5 \%$ glucose (BTR-G) or $0.5 \%$ sorbitol (BTR-S) was utilized for

224 growth assays. For experiments comparing the growth of WT, DEL, and COMP strains, $1 \mathrm{mg} / \mathrm{ml}$

225 spectinomycin was added to the growth media to retain the pDL278 plasmid. All growth assays

226 were done at $37^{\circ} \mathrm{C}$ in an anaerobic chamber (5\% hydrogen, $5 \%$ carbon dioxide, $90 \%$ nitrogen).

\section{Phenotypic microarray}

229 Biolog Phenotypic microarray assays were conducted per manufacturer's recommendations (36).

230 Briefly, overnight cultures from single bacterial colonies were diluted in fresh Brain Heart

231 Infusion (BHI) broth and grown to an $\mathrm{OD}_{600}$ of $0.6-0.7$ at $37^{\circ} \mathrm{C}$ in an anaerobic chamber. Cells

232 were collected via centrifugation $(3,000 \mathrm{xg}, 5 \mathrm{~min})$ and washed twice with PBS and resuspended

233 to an $\mathrm{OD}_{600}$ of 0.4 in IF-0a GN/GP base. Inoculating fluid was prepared and combined with cells

234 at $81 \%$ turbidity and $100 \mu \mathrm{l}$ of the mixture was added to each well and overlaid with $40 \mu 1$ 
235 mineral oil. Temperature was maintained at $37^{\circ} \mathrm{C}$ while absorbance values at $590 \mathrm{~nm}$ and $750 \mathrm{~nm}$

236 were collected every 20 min for 24 h using a Multiskan Spectrum plate reader (Thermo Fischer

237 Scientific). Results were obtained by subtracting the measurements at $750 \mathrm{~nm}$ from those at 590

$238 \mathrm{~nm}$, and the average of two replicates was used to construct a growth curve for each well.

\section{0 sRNA discovery}

241 Bacterial cultures were grown in $\mathrm{BHI}$ broth to an $\mathrm{OD}_{600}$ of $0.5-0.6$. RNA stop solution (5\%

242 Phenol, 95\% Ethanol) was added to bacterial cultures (1.25 mL stop solution per $10 \mathrm{~mL}$ culture)

243 and cells were pelleted by centrifugation at $10,000 \mathrm{xg}$ for $10 \mathrm{~min}$ at $4^{\circ} \mathrm{C}$. Bacterial pellets were

244 resuspended in $1 \mathrm{ml}$ of TRI reagent (Thermo Fischer Scientific) and total RNA was extracted

245 using the manufacturer's protocol. RNA was resuspended in nuclease-free water and DNA was

246 removed by TURBO DNase (Thermo Fischer Scientific) treatment. RNA sequencing was

247 performed at the Yale Center for Genome Analysis using Illumina NovaSeq (paired-end, 150

248 bp). Raw reads have been deposited in the NCBI Sequence Read Archive under the accession

249 number PRJNA726731. RNA-seq reads were processed using Trimmomatic to remove low-

250 quality reads and adapters (49). CLC Genomics workbench was used to map the reads to the $S$.

251 mutans UA159 genome (NC_004350.2) and to determine the total read count for each gene.

252 Coverage plots were generated by calculating reads mapped per nucleotide across the entire

253 genome using an in-house Perl script, as described previously (13). The Artemis genome

254 browser (50) was used for visual inspection of transcriptomics data and gggenes package in $\mathrm{R}$

255 (version 0.4.1) was used to draw Figure 1. The putative $5^{\prime}$ end of each sRNA was estimated from

256 sites on transcriptional coverage plots with sharp increases in reads mapped per nucleotide.

257 RNAalifold was used to predict secondary structure of SmsR4 and 6S RNA (51), and ARNold 
258 was used to predict 3' Rho-independent terminator structures (52). For sRNAs without predicted

259 terminators, $3^{\prime}$ ends were defined as sites on transcriptional coverage plots with a sharp decrease

260 in reads mapped per nucleotide. Potential open reading frames (ORFs) within sRNA genes were

261 detected using ORF Finder (53).

262

\section{Stress induction}

264 Overnight cultures of $S$. mutans UA159 were diluted 1:100 in BTR-G and grown to an OD 600 of

$265 \quad 0.3-0.4$ at $37^{\circ} \mathrm{C}$ in an anaerobic chamber. To induce sugar-phosphate stress, $6 \%$ xylitol in BTR

266 broth was added to one half (treatment) and grown for 15 minutes at $37^{\circ} \mathrm{C}$, while an equal

267 volume of BTR broth without xylitol was added to the control and incubated under the same

268 conditions. Similarly, for oxidative stress induction, $1 \mathrm{mM} \mathrm{H}_{2} \mathrm{O}_{2}$ was added to one half of the

269 culture (treatment) while an equal volume of water was added to the control half and incubated

270 for 15 minutes. For heat stress, one half of the culture was incubated at $37^{\circ} \mathrm{C}$ for 15 minutes

271 (control), while the other was incubated at $45^{\circ} \mathrm{C}$ for 15 minutes (treatment). To induce acid

272 stress, cultures were centrifuged and one half was resuspended in BTR-G, pH 7 (control), while

273 the other half was resuspended in BTR-G, $\mathrm{pH} 5$ (treatment), and incubated for 30 minutes at

$27437^{\circ} \mathrm{C}$. Anaerobic conditions were maintained throughout the stress induction assays. RNA was

275 extracted as described above. To confirm stress induction, qRT-PCR was used to measure the

276 expression of stress marker genes previously associated with each tested stress condition (54-57)

277 (Figure S4). Contaminating DNA was removed by TURBO DNase (Thermo Fischer Scientific)

278 treatment and cDNA was synthesized with a High-Capacity cDNA Reverse Transcription Kit

279 (Thermo Fischer Scientific) using random primers. qRT-PCR was performed using SYBR Green

280 master mix (Thermo Fischer Scientific) and gene-specific primers (Table S2). RNA was 
281 sequenced and RNA-seq reads were processed as described above. The DESeq2 package in R

282 was used to determine differential gene expression of sRNAs under the four stress-inducing

283 conditions compared to controls (58). Experiments were performed in triplicate for all conditions

284 except for acid stress, which was performed in duplicate.

286 In vitro transcription

287 Amplification of gDNA for in vitro transcription was performed using PCR primers designed to 288 incorporate a T7 promoter (Table S2). PCR products to be used as DNA templates were cleaned 289 using a NucleoSpin Gel and PCR Clean-up kit (Takara Bio). In vitro transcription was performed 290 using MAXIscript T7 Transcription Kit (Thermo Fischer Scientific) per manufacturer's protocol 291 with a maximum of $1 \mu \mathrm{g}$ of DNA used as template. Following TURBO DNase treatment, RNA was purified using a Monarch RNA Cleanup Kit (New England Biolabs).

294 Northern blot

295 RNA was isolated from S. mutans cells under sugar-phosphate stress, oxidative, heat, or acid 296 stress as described above. Equal amounts of RNA were adjusted to $10 \mu$ with nuclease-free 297 water, and $10 \mu \mathrm{l}$ of 2x RNA loading dye (Thermo Fischer Scientific) was added and incubated 298 for $10 \mathrm{~min}$ at $70^{\circ} \mathrm{C}$ followed by $3 \mathrm{~min}$ on ice. Samples were loaded onto either $6 \%$ or $10 \% \mathrm{TBE}$ 299 Urea Gel (Thermo Fischer Scientific) along with a biotinylated sRNA ladder (Kerafast). Gels

300 were run in $1 \mathrm{x}$ TBE buffer at $180 \mathrm{~V}$ for $60 \mathrm{~min}(6 \%$ gels $)$ or $180 \mathrm{~V}$ for $80 \mathrm{~min}(10 \%$ gels $)$. RNA 301 was transferred to a Biodyne B Nylon Membrane (Thermo Fischer Scientific) using the BioRad 302 Mini-Trans Blot at $12 \mathrm{~V}$ overnight, $4^{\circ} \mathrm{C}$ in $0.5 \mathrm{x}$ TBE buffer. Membranes were UV-crosslinked 303 using a Staralinker 2400 UV Crosslinker $(1200 \mathrm{~mJ})$ and were moved to glass hybridization 
304 chambers and prehybridized using $10 \mathrm{ml}$ of ULTRAhyb-Oligo Buffer (Thermo Fischer

305 Scientific) at $45^{\circ} \mathrm{C}$ for $2 \mathrm{~h}$ with rotation. RNA probes produced from in vitro transcription as

306 described above were heated at $95^{\circ} \mathrm{C}$ for $5 \mathrm{~min}$ and cooled on ice for $3 \mathrm{~min}$, then added to fresh

307 hybridization buffer. Membranes were incubated overnight at $45^{\circ} \mathrm{C}$ with rotation. After washing,

308 membranes were incubated for $2 \mathrm{~h}$ with shaking in Licor Intercept Blocking Buffer with 1\% SDS

309 at room temperature. Blocking buffer was removed and membranes were incubated in

310 Streptavidin-IRDye $800 \mathrm{CW}$ diluted 1:20,000 in Licor Intercept Blocking Buffer with 1\% SDS

311 for $30 \mathrm{~min}$. Blots were washed and viewed on a Licor Odyssey scanner.

\section{EMSA and mutagenesis}

314 Electromobility shift assay (EMSA) was performed as described previously (59). Briefly, a DNA

315 template was amplified from $S$. mutans UA159 gDNA using primers with a T7 tag (Table S2).

316 RNA was transcribed from this template using the MAXI T7 Transcription Kit that incorporated

317 biotinylated uracil into the sRNA transcript. RNA was purified with a Monarch RNA Cleanup

318 Kit and resuspended in TE buffer. SmsR4 and SMU_313 transcripts were combined at ratios

319 shown in Figure 7 and heated for $5 \mathrm{~min}$ at $85^{\circ} \mathrm{C}$, then immersed in ice for $30 \mathrm{sec}$. The reaction

320 volume was adjusted to $10 \mu \mathrm{l}$ with $5 \mathrm{x}$ TMN buffer and incubated at $37^{\circ} \mathrm{C}$ for $30 \mathrm{~min}$. Samples

321 were run on an $8 \%$ TBE gel (Thermo Fischer Scientific) for 90 min at $100 \mathrm{~V}$ in 1x TBE buffer.

322 The gel was transferred to a Biodyne B Membrane overnight at $12 \mathrm{~V}, 4^{\circ} \mathrm{C}$ in $0.5 \mathrm{x}$ TBE.

323 Membranes were crosslinked, blocked, and probed with Strepatvidin-IRDye 800CW as

324 described above for Northern blot assays, and images were examined on a Licor Odyssey

325 scanner. SMU_313 with mutated SmsR4-binding site was constructed using the Q5 Mutagenesis

326 Kit (New England Biolabs) and mutations were confirmed through Sanger sequencing. 


\section{Gene deletion and complementation}

329 SmsR4- and SMU_313-deletion strains were constructed using the markerless-mutagenic system

330 and an IDFC2 selection and counter-selection cassette, as described previously (60).

331 Complementation was preformed using the pDL278 plasmid designed for expression in both $E$.

332 coli and $S$. mutans $(31,32)$. The plasmid was purified from E. coli using a Plasmid MiniPrep kit

333 (Thermo Fischer Scientific). pDL278 was linearized using BamHI and EcoRI, and PCR products

334 (Table S2) were ligated into the linearized plasmid using T4 ligase (Thermo Fischer Scientific).

335 Plasmids were then transformed into competent E. coli DH5-alpha cells following

336 manufacturer's protocol (New England Biolabs). Sanger sequencing was used to confirm

337 plasmid construction. Purified plasmids were transformed into S. mutans using competence

338 stimulating peptide as described previously (60).

\section{RACE assay}

341 Rapid Amplification of cDNA Ends (RACE) was performed using a RACE kit (Thermo Fisher

342 Scientific) per the manufacturer's recommendations. 5' RACE assay was conducted using a gene

343 specific primer (GSP) complementary to the 3' end of SmsR4 (Table S2). RNA degradation,

344 cDNA synthesis, and TdT tailing were accomplished using kit components and manufacturer

345 protocols. A second nested GSP was used to amplify the tailed cDNA, and the PCR product from

346 this reaction was cloned into pGEM T-Easy vector (Promega), transformed into competent DH5-

347 alpha E. coli and the 5' end of SmsR4 was determined using Sanger sequencing. For the 3'

348 RACE assay, Poly-A polymerase (New England Biolabs) was used to add poly-A tails to all

349 transcripts. Precipitated poly-A tailed RNA was reverse transcribed using an oligo-dT adapter 
350 primer and SuperScript II reverse transcriptase. RNA was subsequently degraded using RNase

351 H. A GSP designed to bind to the 5' end of SmsR4 and an Abridged Universal Amplification

352 Primer (Table S2) were used to amplify the cDNA, and PCR products were cloned into pGEM

353 T-Easy vector, transformed into competent E. coli DH5-alpha cells and the 3' end of SmsR4 was

354 identified using Sanger sequencing.

356 Covariance modeling

357 Covariance models of sRNAs were constructed as previously described $(61,62)$. Briefly, SmsR4

358 and 6 S sequences from $S$. mutans UA159 were used as queries in BlastN searches against all

359 Streptococcus genomes available in RefSeq $(63,64)$. Hits with $>65 \%$ identity and $>70 \%$

360 coverage were retained and five and six sequences were randomly selected to serve as seed

361 sequences for constructing $6 \mathrm{~S}$ and SmsR4 covariance models, respectively (Table S3). The

362 WAR webserver was used to align the seed sequences and the Infernal suite of tools (v1.1.2) was

363 used to construct (cmbuild) and calibrate (cmcalibrate) an initial covariance model for each

364 sRNA $(65,66)$. This model was used to search ( $\mathrm{cmsearch})$ a database constructed from 37

365 representative Streptococcus full genomes available on RefSeq (Table S4). Results from

366 cmsearch with an e-value $<1$ e-5 were used to add unrepresented sequences to the query model,

367 which was then refined, recalibrated, and used for another round of cmsearch. This process was

368 repeated for each sRNA until cmsearch failed to yield new unrepresented sequences. The final

369 models were used to determine the prevalence of $6 \mathrm{~S}$ and SmsR4 in 62 full and partial

370 Streptococcus genomes (Table S5). The presence or absence of each sRNAs was mapped on a

371 previously published phylogenetic tree (29) and nodes of sRNA origin and secondary loss were

372 determined through maximum parsimony. 


\section{In silico $\mathbf{S R A}$ target prediction}

375 For SmsR4 target prediction using IntaRNA (67), SmsR4 sequence as determined by RACE

376 assay was used as input and searched against the $S$. mutans UA159 genome using default

377 parameters (75 $\mathrm{nt}$ upstream and downstream from the translation start site, one interaction per

378 pair, $7 \mathrm{nt}$ hybridization seed). Target RNA2 (68) was run using the same query sequence and

379 default parameters ( $80 \mathrm{nt}$ upstream and $20 \mathrm{nt}$ downstream from the translation start site, $7 \mathrm{nt}$

380 hybridization seed). IntaRNA was also used to predict targets for 11 other sRNAs using stricter

381 parameters to identify potential interactions adjacent to translation start sites of mRNA targets.

382 For all in silico target predictions, only significant results $(\mathrm{p}<0.05$, as determined by IntaRNA

383 or Target RNA2) were retained.

\section{ACKNOWLEDGEMENTS}

386 We thank Zhengzhong Zou and Samantha Fancher for their assistance with experiments, and

387 Shaun Wachter for technical advice. This work was supported in part by National Institute of

388 Dental and Craniofacial Research grants DE028409 to RR and DE028252 to JM. 


\section{REFERENCES}

392 1. Forssten SD, Björklund M, Ouwehand AC. 2010. Streptococcus mutans, caries and

393 simulation models. Nutrients 2:290-298.

394 2. Hamada S, Koga T, Ooshima T. 1984. Virulence factors of Streptococcus mutans and 395 dental caries prevention. J Dent Res 63:407-411.

396 3. Loesche WJ. 1986. Role of Streptococcus mutans in human dental decay. Microbiol Rev $397 \quad 50: 353-380$.

398 4. Bowen WH, Burne RA, Wu H, Koo H. 2018. Oral biofilms: pathogens, matrix, and 399 polymicrobial interactions in microenvironments. Trends Microbiol 26:229-242.

400 5. Ajdić D, McShan WM, McLaughlin RE, Savić G, Chang J, Carson MB, Primeaux C, Tian 401 R, Kenton S, Jia H, Lin S, Qian Y, Li S, Zhu H, Najar F, Lai H, White J, Roe BA, Ferretti 402 JJ. 2002. Genome sequence of Streptococcus mutans UA159, a cariogenic dental pathogen. $403 \quad$ Proc Natl Acad Sci U S A 99:14434-14439.

404 6. Lemos JA, Palmer SR, Zeng L, Wen ZT, Kajfasz JK, Freires IA, Abranches J, Brady LJ. 2019. The biology of Streptococcus mutans. Microbiol Spectr 7.

406 7. Deutscher J, Francke C, Postma PW. 2006. How phosphotransferase system-related protein 407 phosphorylation regulates carbohydrate metabolism in bacteria. Microbiol Mol Biol Rev $408 \quad 70: 939-1031$. 
409 8. Takahashi-Abbe S, Abbe K, Takahashi N, Tamazawa Y, Yamada T. 2001. Inhibitory effect

410 of sorbitol on sugar metabolism of Streptococcus mutans in vitro and on acid production in

411 dental plaque in vivo. Oral Microbiol Immunol 16:94-99.

412 9. Mäkinen KK. 2010. Sugar alcohols, caries incidence, and remineralization of caries lesions:

413 a literature review. Int J Dent 2010:981072.

414 10. Lemos JA, Burne RA. 2008. A model of efficiency: stress tolerance by Streptococcus

$415 \quad$ mutans. Microbiology (Reading) 154:3247-3255.

416 11. Storz G, Vogel J, Wassarman KM. 2011. Regulation by small RNAs in bacteria: expanding 417 frontiers. Mol Cell 43:880-891.

418 12. Holmqvist E, Wagner EGH. 2017. Impact of bacterial sRNAs in stress responses. Biochem $419 \quad$ Soc Trans 45:1203-1212.

420 13. Raghavan R, Groisman EA, Ochman H. 2011. Genome-wide detection of novel regulatory $421 \quad$ RNAs in Escherichia coli. Genome Res 21:1487-1497.

422 14. Warrier I, Hicks LD, Battisti JM, Raghavan R, Minnick MF. 2014. Identification of novel 423 small RNAs and characterization of the 6S RNA of Coxiella burnetii. PLoS One $424 \quad 9: \mathrm{e} 100147$.

425 15. Wachter S, Hicks LD, Raghavan R, Minnick MF. 2020. Novel small RNAs expressed by 426 Bartonella bacilliformis under multiple conditions reveal potential mechanisms for 427 persistence in the sand fly vector and human host. PLoS Negl Trop Dis 14:e0008671. 
428 16. Kalvari I, Argasinska J, Quinones-Olvera N, Nawrocki EP, Rivas E, Eddy SR, Bateman A, 429 Finn RD, Petrov AI. 2018. Rfam 13.0: shifting to a genome-centric resource for non-coding $430 \quad$ RNA families. Nucleic Acids Res 46:D335-D342.

431 17. Zeng L, Choi SC, Danko CG, Siepel A, Stanhope MJ, Burne RA. 2013. Gene regulation by 432 CcpA and catabolite repression explored by RNA-Seq in Streptococcus mutans. PLoS One $433 \quad 8: \mathrm{e} 60465$.

434 18. Jester BC, Romby P, Lioliou E. 2012. When ribonucleases come into play in pathogens: a 435 survey of gram-positive bacteria. International Journal of Microbiology 2012:e592196.

436 19. Mars RAT, Nicolas P, Denham EL, van Dijl JM. 2016. Regulatory RNAs in Bacillus 437 subtilis: a gram-positive perspective on bacterial RNA-mediated regulation of gene 438 expression. Microbiol Mol Biol Rev 80:1029-1057.

439 20. Menendez-Gil P, Toledo-Arana A. 2021. Bacterial 3' UTRs: a useful resource in post$440 \quad$ transcriptional regulation. Front Mol Biosci 7:617633.

441 21. Merritt J, Chen Z, Liu N, Kreth J. 2014. Posttranscriptional regulation of oral bacterial 442 adaptive responses. Curr Oral Health Rep 1:50-58.

443 22. Mohanty BK, Kushner SR. 2018. Enzymes involved in post-transcriptional RNA 444 metabolism in gram-negative bacteria. Microbiol Spectr 6:10.1128/microbiolspec.RWR$445 \quad 0011-2017$. 
23. Sinha D, Zimmer K, Cameron TA, Rusch DB, Winkler ME, De Lay NR. 2019. Redefining the small regulatory RNA transcriptome in Streptococcus pneumoniae serotype 2 strain D39. J Bacteriol 201:e00764-18.

24. Barrick JE, Sudarsan N, Weinburg Z, Ruzzo WL, Breaker RR. 2005. 6S RNA is a widespread regulator of eubacterial RNA polymerase that resembles an open promoter.

25. Cavanagh AT, Wassarman KM. 2014. 6S RNA, a global regulator of transcription in RNA 11:774-784.

26. Trotochaud AE, Wassarman KM. 2005. A highly conserved 6S RNA structure is required for regulation of transcription. Nat Struct Mol Biol 12:313-319.

27. Belda E, Sekowska A, Le Fèvre F, Morgat A, Mornico D, Ouzounis C, Vallenet D, Médigue C, Danchin A. 2013. An updated metabolic view of the Bacillus subtilis 168 genome. Microbiology (Reading) 159:757-770.

28. Chae H, Han K, Kim K, Park H, Lee J, Lee Y. 2011. Rho-dependent termination of ssrS (6S RNA) transcription in Escherichia coli. J Biol Chem 286:114-122.

29. Patel S, Gupta RS. 2018. Robust demarcation of fourteen different species groups within the genus Streptococcus based on genome-based phylogenies and molecular signatures. Infection, Genetics and Evolution 66:130-151. phenotypic testing and assay of gene function. Genome Res 11:1246-1255. 
31. LeBlanc DJ, Lee LN, Abu-Al-Jaibat A. 1992. Molecular, genetic, and functional analysis of the basic replicon of pVA380-1, a plasmid of oral streptococcal origin. Plasmid 28:130145.

32. Zhou L, Manias DA, Dunny GM. 2000. Regulation of intron function: efficient splicing in vivo of a bacterial group II intron requires a functional promoter within the intron. Mol Microbiol 37:639-651. transcripts reveals $3^{\prime}$ UTRs as a genomic reservoir of regulatory small RNAs. EMBO J

34. Hoyos M, Huber M, Förstner KU, Papenfort K. 2020. Gene autoregulation by 3' UTRderived bacterial small RNAs. Elife 9:e58836.

35. Lalaouna D, Baude J, Wu Z, Tomasini A, Chicher J, Marzi S, Vandenesch F, Romby P, Caldelari I, Moreau K. 2019. RsaC sRNA modulates the oxidative stress response of Staphylococcus aureus during manganese starvation. Nucleic Acids Res 47:9871-9887.

36. Miyakoshi M, Chao Y, Vogel J. 2015. Regulatory small RNAs from the 3' regions of bacterial mRNAs. Curr Opin Microbiol 24:132-139. ArgR and the sRNA derived from the 3'-UTR region of its gene, ArgX, both regulate the arginine deiminase pathway in Lactococcus lactis. PLoS One 14:e0218508. 
485 38. Adams PP, Baniulyte G, Esnault C, Chegireddy K, Singh N, Monge M, Dale RK, Storz G, Wade JT. 2021. Regulatory roles of Escherichia coli 5' UTR and ORF-internal RNAs detected by $3^{\prime}$ end mapping. eLife 10:e62438.

39. Garst AD, Edwards AL, Batey RT. 2011. Riboswitches: structures and mechanisms. Cold Spring Harb Perspect Biol 3:a003533.

40. Jose BR, Gardner PP, Barquist L. 2019. Transcriptional noise and exaptation as sources for bacterial sRNAs. Biochem Soc Trans 47:527-539.

41. Lybecker M, Bilusic I, Raghavan R. 2014. Pervasive transcription: detecting functional RNAs in bacteria. Transcription 5:e944039. Spectrum 6:6.5.06.

43. Deutscher J, Aké FMD, Derkaoui M, Zébré AC, Cao TN, Bouraoui H, Kentache T, Mokhtari A, Milohanic E, Joyet P. 2014. The bacterial phosphoenolpyruvate:carbohydrate phosphotransferase system: regulation by protein phosphorylation and phosphorylationdependent protein-protein interactions. Microbiology and Molecular Biology Reviews

44. Richards GR, Patel MV, Lloyd CR, Vanderpool CK. 2013. Depletion of glycolytic intermediates plays a key role in glucose-phosphate stress in Escherichia coli. J Bacteriol $195: 4816-4825$. 
504 45. Bobrovskyy M, Vanderpool CK. 2014. The small RNA SgrS: roles in metabolism and pathogenesis of enteric bacteria. Front Cell Infect Microbiol 4:61.

46. Rice JB, Vanderpool CK. 2011. The small RNA SgrS controls sugar-phosphate accumulation by regulating multiple PTS genes. Nucleic Acids Res 39:3806-3819.

47. Jeng W-Y, Panjaitan NSD, Horng Y-T, Chung W-T, Chien C-C, Soo P-C. 2017. The negative effects of KPN00353 on glycerol kinase and microaerobic 1,3-propanediol production in Klebsiella pneumoniae. Front Microbiol 8:2441.

48. Choi J, Shin D, Yoon H, Kim J, Lee C-R, Kim M, Seok Y-J, Ryu S. 2010. Salmonella pathogenicity island 2 expression negatively controlled by EIIANtr-SsrB interaction is required for Salmonella virulence. Proc Natl Acad Sci U S A 107:20506-20511.

49. Bolger AM, Lohse M, Usadel B. 2014. Trimmomatic: a flexible trimmer for Illumina sequence data. Bioinformatics 30:2114-2120.

50. Rutherford K, Parkhill J, Crook J, Horsnell T, Rice P, Rajandream M-A, Barrell B. 2000. Artemis: sequence visualization and annotation. Bioinformatics 16:944-945. Biol 395:527-544. for the prediction of Rho-independent transcription terminators. RNA Biol 8:11-13. formatting protein and DNA sequences. Biotechniques 28:1102, 1104. 
54. Decker E-M, Klein C, Schwindt D, von Ohle C. 2014. Metabolic activity of Streptococcus mutans biofilms and gene expression during exposure to xylitol and sucrose. Int J Oral Sci 6:195-204.

55. Gong Y, Tian X-L, Sutherland T, Sisson G, Mai J, Ling J, Li Y-H. 2009. Global transcriptional analysis of acid-inducible genes in Streptococcus mutans: multiple twocomponent systems involved in acid adaptation. Microbiology (Reading) 155:3322-3332.

56. Kajfasz JK, Ganguly T, Hardin EL, Abranches J, Lemos JA. 2017. Transcriptome responses of Streptococcus mutans to peroxide stress: identification of novel antioxidant pathways regulated by Spx. Sci Rep 7:16018.

57. Liu C, Niu Y, Zhou X, Zheng X, Wang S, Guo Q, Li Y, Li M, Li J, Yang Y, Ding Y, Lamont RJ, Xu X. 2015. Streptococcus mutans copes with heat stress by multiple transcriptional regulons modulating virulence and energy metabolism. Sci Rep 5:12929.

58. Love MI, Huber W, Anders S. 2014. Moderated estimation of fold change and dispersion for RNA-seq data with DESeq2. Genome Biology 15:550.

59. Wachter S, Bonazzi M, Shifflett K, Moses AS, Raghavan R, Minnick MF. A CsrA-binding, trans-acting sRNA of Coxiella burnetii is necessary for optimal intracellular growth and vacuole formation during early infection of host cells. Journal of Bacteriology 201:e0052419.

60. Xie Z, Okinaga T, Qi F, Zhang Z, Merritt J. 2011. Cloning-independent and counterselectable markerless mutagenesis system in Streptococcus mutans. Appl Environ Microbiol 77:8025-8033. 
61. Barquist L, Burge SW, Gardner PP. 2016. Studying RNA homology and conservation with Infernal: from single sequences to RNA families. Curr Protoc Bioinformatics 54:12.13.112.13.25.

62. Krieger MC, Dutcher HA, Ashford AJ, Raghavan R. 2021. A peroxide-responding sRNA evolved from a peroxidase mRNA. bioRxiv doi: https://doi.org/101101/20211018464853 2021.10.18.464853.

63. Altschul SF, Gish W, Miller W, Myers EW, Lipman DJ. 1990. Basic local alignment search tool. J Mol Biol 215:403-410.

64. O’Leary NA, Wright MW, Brister JR, Ciufo S, Haddad D, McVeigh R, Rajput B,

Robbertse B, Smith-White B, Ako-Adjei D, Astashyn A, Badretdin A, Bao Y, Blinkova O,

Brover V, Chetvernin V, Choi J, Cox E, Ermolaeva O, Farrell CM, Goldfarb T, Gupta T,

Haft D, Hatcher E, Hlavina W, Joardar VS, Kodali VK, Li W, Maglott D, Masterson P,

McGarvey KM, Murphy MR, O’Neill K, Pujar S, Rangwala SH, Rausch D, Riddick LD,

Schoch C, Shkeda A, Storz SS, Sun H, Thibaud-Nissen F, Tolstoy I, Tully RE, Vatsan AR,

Wallin C, Webb D, Wu W, Landrum MJ, Kimchi A, Tatusova T, DiCuccio M, Kitts P, Murphy TD, Pruitt KD. 2016. Reference sequence (RefSeq) database at NCBI: current

65. Torarinsson E, Lindgreen S. 2008. WAR: Webserver for aligning structural RNAs. Nucleic Acids Res 36:W79-W84.

66. Nawrocki EP, Eddy SR. 2013. Infernal 1.1: 100-fold faster RNA homology searches.

$$
\text { Bioinformatics 29:2933-2935. }
$$


bioRxiv preprint doi: https://doi.org/10.1101/2021.11.16.468913; this version posted November 17, 2021. The copyright holder for this preprint

(which was not certified by peer review) is the author/funder, who has granted bioRxiv a license to display the preprint in perpetuity. It is made available under aCC-BY-NC-ND 4.0 International license.

566 67. Mann M, Wright PR, Backofen R. 2017. IntaRNA 2.0: enhanced and customizable

567 prediction of RNA-RNA interactions. Nucleic Acids Res 45:W435-W439.

568 68. Kery MB, Feldman M, Livny J, Tjaden B. 2014. TargetRNA2: identifying targets of small

569 regulatory RNAs in bacteria. Nucleic Acids Res 42:W124-W129. 
Table 1. Novel sRNAs in S. mutans.

\begin{tabular}{|c|c|c|c|c|c|c|c|c|}
\hline $\mathbf{s R N A} \mathbf{A}^{\mathrm{a}}$ & $\begin{array}{c}\text { Rfam } \\
\text { annot- } \\
\text { ation }^{\mathrm{b}}\end{array}$ & $\begin{array}{c}\text { Previous } \\
\text { prediction }^{\mathrm{c}}\end{array}$ & $\begin{array}{l}\text { Bordering } \\
\text { gene (left) }\end{array}$ & $\begin{array}{l}\text { sRNA left } \\
\text { bound }^{d}\end{array}$ & $\begin{array}{c}\text { sRNA } \\
\text { right } \\
\text { bound }^{d}\end{array}$ & $\begin{array}{l}\text { Bordering } \\
\text { gene (right) }\end{array}$ & 冚 & $\begin{array}{l}\text { Predicted } \\
\text { size (nt) }\end{array}$ \\
\hline SmsR1 & & & SMU_61 & 62597 & 62953 & SMU_63c & $\mathrm{F}$ & 357 \\
\hline SmsR2 & & psRNA-31 & SMU_97 & 99488 & 99909 & SMU_t19 & $\mathrm{R}$ & 422 \\
\hline SmsR3 & & psRNA-54 & SMU_219 & 211498 & 211709 & SMU_220c & $\mathrm{R}$ & 212 \\
\hline SmsR4 & & psRNA-62 & SMU_318 & 303748 & 303857 & SMU_320 & $\mathrm{R}$ & 110 \\
\hline SmsR5 & $\begin{array}{c}\text { RNase } \\
\mathrm{P}\end{array}$ & psRNA-73 & SMU_471 & 439833 & 440221 & SMU_472 & $\mathrm{F}$ & 389 \\
\hline SmsR6 & & psRNA-78 & SMU_530c & 497858 & 498119 & SMU_531 & $\mathrm{F}$ & 262 \\
\hline SmsR7 & & & SMU_1046c & 995311 & 995586 & SMU_1048 & $\mathrm{R}$ & 276 \\
\hline SmsR8 & tmRNA & & SMU_1196c & 1139336 & 1139677 & SMU_1197 & $\mathrm{R}$ & 342 \\
\hline SmsR12 & & $\begin{array}{l}\text { psRNA-204 } \\
\text { psRNA-205 }\end{array}$ & SMU_1862 & 1757885 & 1758495 & SMU_1865 & $\mathrm{R}$ & 611 \\
\hline SmsR14 & $6 \mathrm{~S}$ & psRNA-235 & SMU_2056 & 1929960 & 1930160 & SMU_2057c & $\mathrm{F}$ & 200 \\
\hline SmsR16 & & & SMU_803c & 749489 & 749732 & SMU_804 & $\mathrm{R}$ & 244 \\
\hline SmsR18 & & $\begin{array}{c}\text { psRNA- } \\
132 \\
\end{array}$ & SMU_1332c & 1254431 & 1255035 & SMU_1334 & $\mathrm{R}$ & 605 \\
\hline SmsR19 & & & SMU_1398 & 1327742 & 1328337 & SMU_1400c & $\mathrm{R}$ & 596 \\
\hline SmsR20 & & psRNA-150 & SMU_1512 & 1439375 & 1439585 & SMU_1513 & $\mathrm{R}$ & 211 \\
\hline SmsR22 & & & SMU_1703 & 1614938 & 1615314 & SMU_1704 & $\mathrm{R}$ & 377 \\
\hline
\end{tabular}

573 a Small RNAs were named SmsR1-SmsR22 (Note: some of the original candidate sRNAs were

574 later excluded from analysis).

575 bxisting Rfam entries for the putative sRNAs.

576 'Previously predicted sRNAs that overlap with our results (17).

577 'The putative 5 ' ends of sRNAs were estimated using visual scans of RNA-seq coverage plots for

578 sites with sharp increases in reads mapped per nucleotide. $3^{\prime}$ ends were estimated based on the

579 locations of predicted terminators (Table 2) or for sRNAs without predicted terminators visual

580 scans of the RNA-seq coverage plots were used to identify sites with sharp drops in reads per

581 nucleotide. SmsR4 boundaries were confirmed using 5' and 3' RACE assays. 
bioRxiv preprint doi: https://doi.org/10.1101/2021.11.16.468913; this version posted November 17,2021 . The copyright holder for this preprint (which was not certified by peer review) is the author/funder, who has granted bioRxiv a license to display the preprint in perpetuity. It is made available under aCC-BY-NC-ND 4.0 International license.

583 Table 2. Predicted promoter and terminator elements of novel sRNAs.

\begin{tabular}{|c|c|c|}
\hline sRNA & -10 Promoter ${ }^{a}$ & Terminator ${ }^{b}$ \\
\hline SmsR1 & $\begin{array}{l}\text { TGTCCTGTTCTTTTTTGAAGGATCAT } \\
\text { TTATAATGAATGATATCAAAAAGAAA }\end{array}$ & $\begin{array}{l}\text { CTAACTAAAACAGAGACTCACATTACAATCAC } \\
\text { ACGTGAATCTCTgTTTTTCTTAGCTG }\end{array}$ \\
\hline SmsR2 & $\begin{array}{l}\text { ACTAAACTATACGTGTATTCGTTTTGT } \\
\text { TGGCAGCCAATTTCTTTAACTATAAC }\end{array}$ & $\begin{array}{l}\text { CAAAAAAAGAAACACCTTCTTAAATCTAGTAA } \\
\text { ATGAGATTTAAGAAGGTGTTTCTTTATAAGCA }\end{array}$ \\
\hline SmsR3 & $\begin{array}{l}\text { ACAGTTGTTTTATCGTTTGTGGAGAAT } \\
\text { ATGATATAATACTAACGGCACAAACT }\end{array}$ & $\begin{array}{l}\text { GTGTAAAAAAAGCCTTAGCTCTGCCAAGCTAG } \\
\text { GGCTTTTCCGTTGCC }\end{array}$ \\
\hline SmsR4 & $\begin{array}{l}\text { АCTTTAAGGTTTCTTTAAGGTTTCTCA } \\
\text { TATATACTTTAATCATCСTAAAАСАA }\end{array}$ & $\begin{array}{l}\text { TTCTTAAAAAACCTTGCAGACTTAAATCTGCA } \\
\text { AGGTTTTTTAATTCG }\end{array}$ \\
\hline SmsR5 & $\begin{array}{l}\text { TGGTAAACAAATTACCGAATAGATTAA } \\
\text { GAAAACGATGCAATTTTTGGATAATC }\end{array}$ & $\begin{array}{l}\text { ATAATAGGTGAGCTAGCTTTGGCTAGCTTTTA } \\
\text { TTGTCTT }\end{array}$ \\
\hline SmsR6 & $\begin{array}{l}\text { GCAAATATGCTTGCAATTCTTTTTTAG } \\
\text { AAAGTGTATAATCGTAAGAAATAAAT }\end{array}$ & $\begin{array}{l}\text { AGATTTAACGCCCTCACACAGATTTTCTGTGT } \\
\text { GAGGTTTTTTGTTATC }\end{array}$ \\
\hline SmsR7 & $\begin{array}{l}\text { CTTTGTTAAGCTTATTTATTATGATAT } \\
\text { AATGAAGTATTCAATTGAAGAAAAAG }\end{array}$ & $\begin{array}{l}\text { TCTTCCAAGTAGCAGAAGCATTGATGTTTCTG } \\
\text { CсаTTTTTAACACAG }\end{array}$ \\
\hline SmsR8 & $\begin{array}{l}\text { TTTTTCCTTAATTTGCTATACTATTT } \\
\text { TCACACAATATGTACTGGGGTCGTTA }\end{array}$ & No terminators found \\
\hline SmsR12 & $\begin{array}{l}\text { TCTTGACAAATGTAAGCGGTTACGATA } \\
\text { AAATAAATTTAGAAAAAAGATAAGAA }\end{array}$ & $\begin{array}{l}\text { AAATAATAAGAGACCCCCAACGATGAGCGTGT } \\
\text { AGATTGTTGGGGGTCTTAATTGTATTGA }\end{array}$ \\
\hline SmsR14 & $\begin{array}{l}\text { TTAACTTGAATTTTTTTAACATTATGG } \\
\text { TATCATATTTAAAGAAGAATTGCTGT }\end{array}$ & No terminators found \\
\hline SmsR16 & $\begin{array}{l}\text { TGAAAGCGTTTTGTTAAACTGACTTTA } \\
\text { GCAAATTATTTGGAGGTAAGGTGCAT }\end{array}$ & No terminators found \\
\hline SmsR18 & $\begin{array}{l}\text { GATAGATAATTTTCATAGTTATTTGTT } \\
\text { AAAAGTGAтATAATAAGAATTATCCG }\end{array}$ & No terminators found \\
\hline SmsR19 & $\begin{array}{l}\text { GCTAGAAAGATTGATTTCTAGCGATTT } \\
\text { TTTAGGTATAATATAAGCAATCAAAA }\end{array}$ & $\begin{array}{l}\text { AATAAGCAAAAGACACTTGAAGCAATAATTCA } \\
\text { AGTGTCTTTTATGGGACTT }\end{array}$ \\
\hline SmsR20 & $\begin{array}{l}\text { CAAGGAAACAAGGCGGGAACGACAAAA } \\
\text { TCATTTCTGTAAATTGCAATGGAATC }\end{array}$ & No terminators found \\
\hline SmsR22 & $\begin{array}{l}\text { AAGAAAACTTGTTATTAACTTTATTTT } \\
\text { TTGATATGCTATAAGTGTCTTCAGGG }\end{array}$ & $\begin{array}{l}\text { TCTTTAGGCCTTCTTTCGATTTGTAAAAATTG } \\
\text { GAGGAaTTTTTTTATGAA }\end{array}$ \\
\hline
\end{tabular}

$584^{a}-10$ promoter elements were determined from a manual scan of sites upstream of transcription

585 start sites (in green) estimated from RNA-seq data. Sites that contained at least 4/6 of the

586 TATAAT consensus promoter sequence, including an A at position two and a $\mathrm{T}$ at position six

587 were identified and are in bold.

$588{ }^{b}$ Intrinsic terminators were predicted by ARNold (52). The predicted stem-loop structure is

589 shown in blue (stem) and red (loop). 
bioRxiv preprint doi: https://doi.org/10.1101/2021.11.16.468913; this version posted November 17, 2021. The copyright holder for this preprint (which was not certified by peer review) is the author/funder, who has granted bioRxiv a license to display the preprint in perpetuity. It is made available under aCC-BY-NC-ND 4.0 International license.

591 Table 3. Stress conditions tested in this study.

\begin{tabular}{|c|c|c|}
\hline Stress Type & Condition & $\begin{array}{c}\text { Exposure } \\
\text { Time }\end{array}$ \\
\hline $\begin{array}{c}\text { Sugar- } \\
\text { phosphate }\end{array}$ & $6 \%$ xylitol & 30 minutes \\
\hline Oxidative & $1 \mathrm{mM} \mathrm{H}_{2} \mathrm{O}_{2}$ & 15 minutes \\
\hline Heat & $45^{\circ} \mathrm{C}$ & 15 minutes \\
\hline Acid & $\mathrm{pH} 5$ & 30 minutes \\
\hline
\end{tabular}

592

593 


\section{FIGURE LEGENDS}

595

596

597

598

599

600

601

602

603

604

605

606

607

608

609

610

611

612

613

614

615

616

Figures 1A and 1B. Expression profiles of novel sRNAs in $\boldsymbol{S}$. mutans. RNA-seq reads mapped to forward (red) and reverse (blue) strands of the S. mutans UA159 genome are shown. Y-axes denote the number of RNA-seq reads mapped to each nucleotide. Genomic locations of novel sRNA genes (black arrows) and flanking genes (grey arrows) along with their nucleotide positions are shown below the coverage plots. Northern blot performed for each sRNA is shown to the right. White arrows denote estimated sizes of sRNAs (Table 1). (Note: intensity between each blot is not comparable as exposure times differed between experiments.)

Figure 2. Differential expression of novel sRNAs in response to stress. Expression values for sRNAs were calculated from the total number of mapped RNA-seq reads. For each sRNA, Log2 fold change between treatment (stress) and control (no stress) samples (+/- standard error) from three replicate experiments are shown, except for acid stress, which used two replicates. Only expression values that were significantly different ( $\mathrm{p} \leq 0.05$, Wald test) between stress and control conditions are displayed.

Figure 3. 6S RNA and SmsR4 are distinct sRNAs. The genome locations and predicted secondary structures of 6S RNAs in Bacillus subtilis, Streptococcus mutans, and Escherichia coli are shown in the top three panels. The genome location and secondary structure of SmsR4 in $S$. mutans is displayed in the bottom panel. Genes that encode $\mathrm{N}$-acetyldiaminopimelate deacetylase and 5-formyltetrahydrofolate cyclo-ligase are abbreviated as N-Ad and 5-FTC, respectively.
(Note: genes are not drawn to scale.) 
617 Figure 4. Prevalence of 6S RNA and SmsR4 in Streptococcus. Presence or absence of 6S and

618 SmsR4 as determined by a covariance modeling-based search is shown. In most species, 6S is

619 present between genes for RarA and tRNA-Lys, whereas SmsR4 is located between genes that

620 encode 5-formyltetrahydrofolate cyclo-ligase (5-FTC) and N-acetyldiaminopimelate deacetylase

621 (N-Ad). Flanking genes other than $\operatorname{rarA}$, tRNA-Lys, 5-FTC, and N-Ad are shown as white

622 arrows. The cladogram is from Patel and Gupta 2018 (29). (Note: genes are not drawn to scale.)

624 Figure 5. SmsR4 promotes $S$. mutans growth in sorbitol-containing medium. Growth of

625 wild-type (WT), SmsR4-deletion (DEL), and SmsR4 complementation (COMP) strains in BTR

626 medium with glucose (BTR-G, left) or sorbitol (BTR-S, right).

628 Figure 6. SmsR4 is predicted to bind to SMU_313. A) Two target prediction algorithms,

629 IntaRNA (67) (left) and TargetRNA2 (68) (right), identified SMU_313 as a potential target of

630 SmsR4. The predicted interaction sites on SmsR4 and 5' untranslated region of SMU_313 are

631 shown, and the start codon (AUG) of SMU_313 has been highlighted. The nucleotides

632 highlighted in red are required for efficient binding of SmsR4 to SMU_313 (see Figure 7). B)

633 Genomic locations of sorbitol phosphotransferase (PTS) system operon, including SMU_313

634 (blue), and SmsR4 (teal) in S. mutans.

636 Figure 7. SmsR4 binds to SMU_313. A) An RNA-RNA electrophoretic mobility shift assay

637 (EMSA) shows that increasing concentrations of SMU_313 with native 5' untranslated sequence

638 binds well to SmsR4. A control lane with unbound SmsR4 is shown to the right. B) SMU_313

639 transcript with a mutated binding site does not interact with SmsR4. A control lane with native 
bioRxiv preprint doi: https://doi.org/10.1101/2021.11.16.468913; this version posted November 17, 2021. The copyright holder for this preprint (which was not certified by peer review) is the author/funder, who has granted bioRxiv a license to display the preprint in perpetuity. It is made available under aCC-BY-NC-ND 4.0 International license.

640 SMU_313 transcript ran on the same gel is shown on the right. The native and mutated SmsR4-

641 binding sites on SMU_313 are shown in red, and start codon is highlighted in yellow.

642 
SUPPLEMENTAL FIGURE LEGENDS

644 Figure S1. Phenotypic microarray. Growth of wild-type (WT) and SmsR4-deletion (DEL)

645 strains in Biolog medium with sorbitol as sole carbon source (30). Values represent the average

646 of two independent growth experiments.

648 Figure S2. Effect of SMU_313 deletion on growth in sorbitol. Growth of SMU_313-deletion

649 (SMU_313 DEL) and wild-type (WT) strains of S. mutans in BTR medium with glucose (BTR-

650 G, left), or sorbitol (BTR-S, right).

651

652 Figure S3. SmsR4 expression over time. Northern blot for SmsR4 in wild-type S. mutans

653 grown in BTR-S was performed at time-points shown. 5S RNA was used as a loading control.

655 Figure S4. Confirmation of stress induction. Either upregulation or downregulation of genes

656 known to be associated with each stress condition were used to confirm stress induction (54-57).

657 Values represent means (+/- standard error) from three independent qPCR assays, except for

658 groES and SMU_1805, which were from two replicates.

660 SUPPLEMENTAL TABLES

661 Table S1. Targets predicted by IntaRNA for novel sRNAs.

662 Table S2. Primers used in this study.

663 Table S3. Genomes used for initial SmsR4 and 6S covariance model construction.

664 Table S4. Genomes used for covariance model calibration.

665 Table S5. Genomes used to determine the prevalence of 6S and SmsR4 in Streptococcus. 


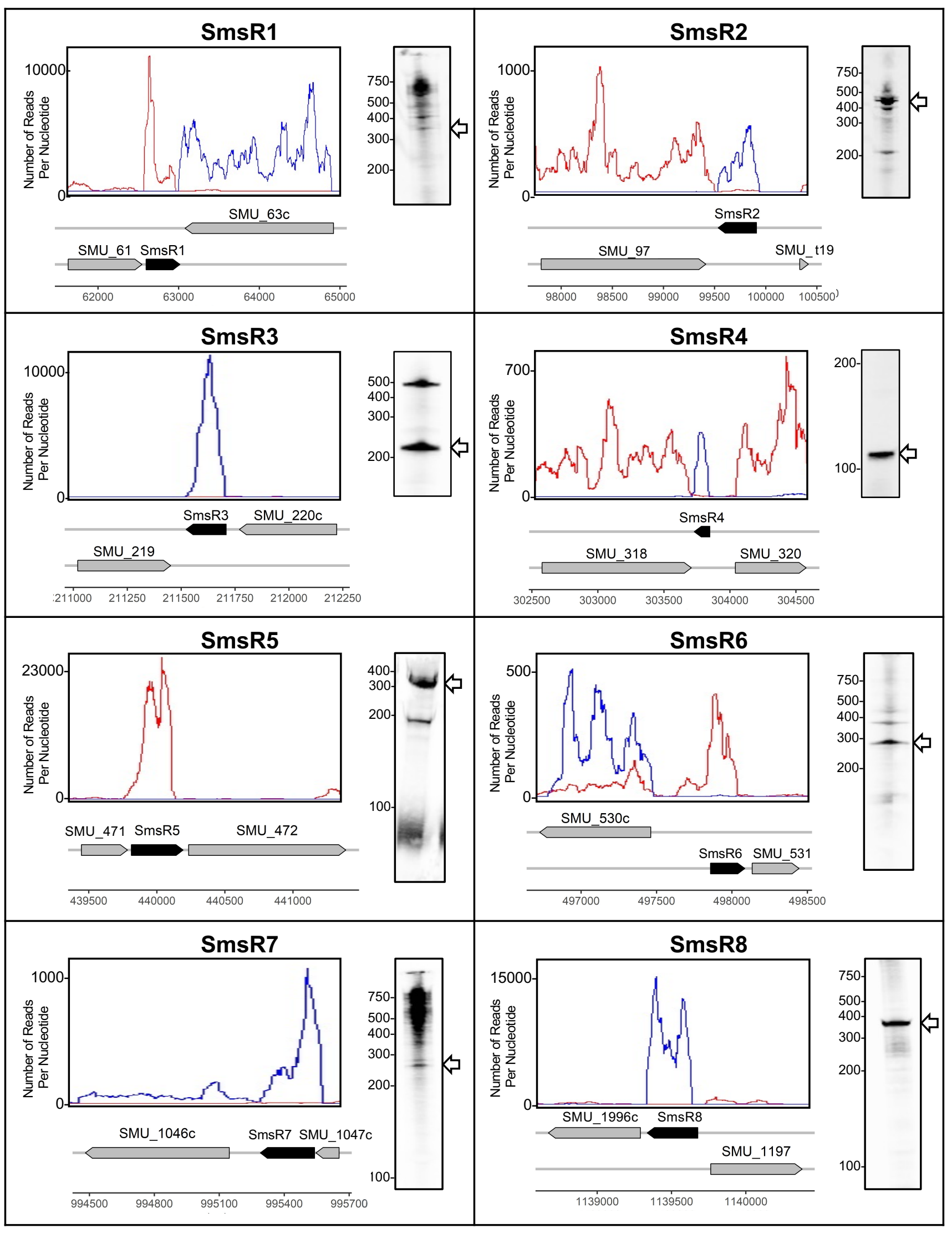


$\square$ Sugar-phosphate $\square$ Acid $\square$ Heat $\square$ Oxidative

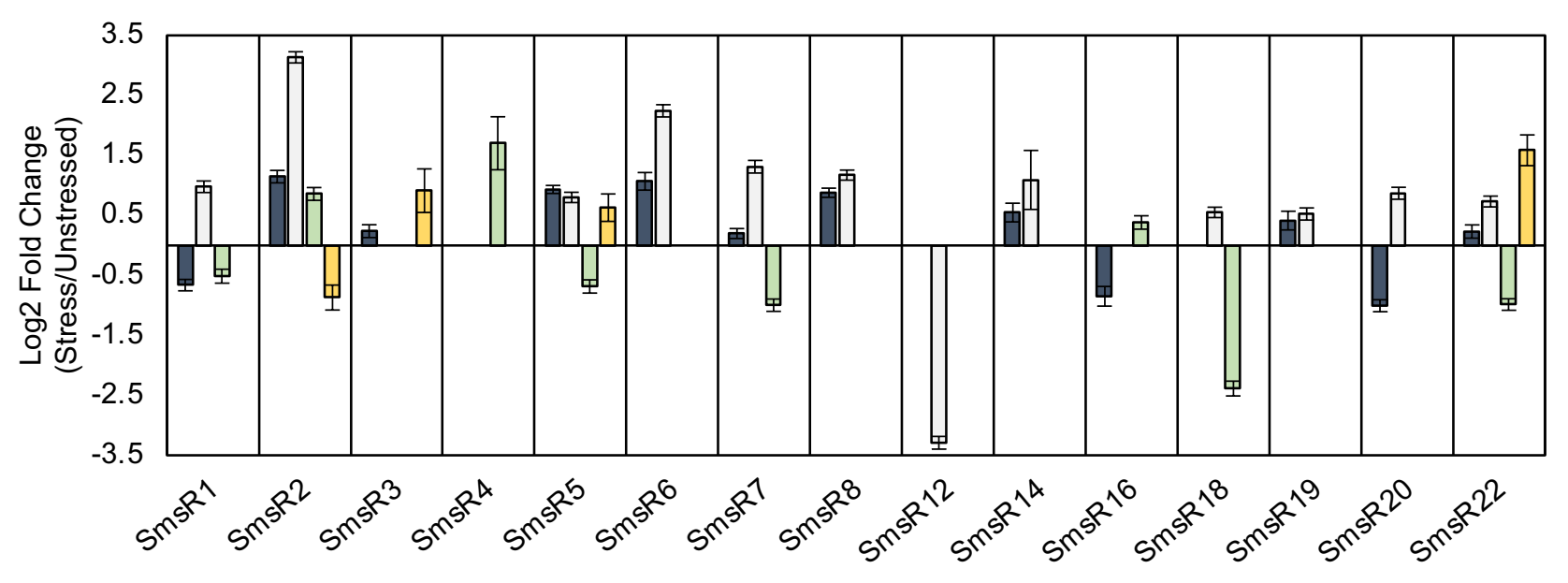




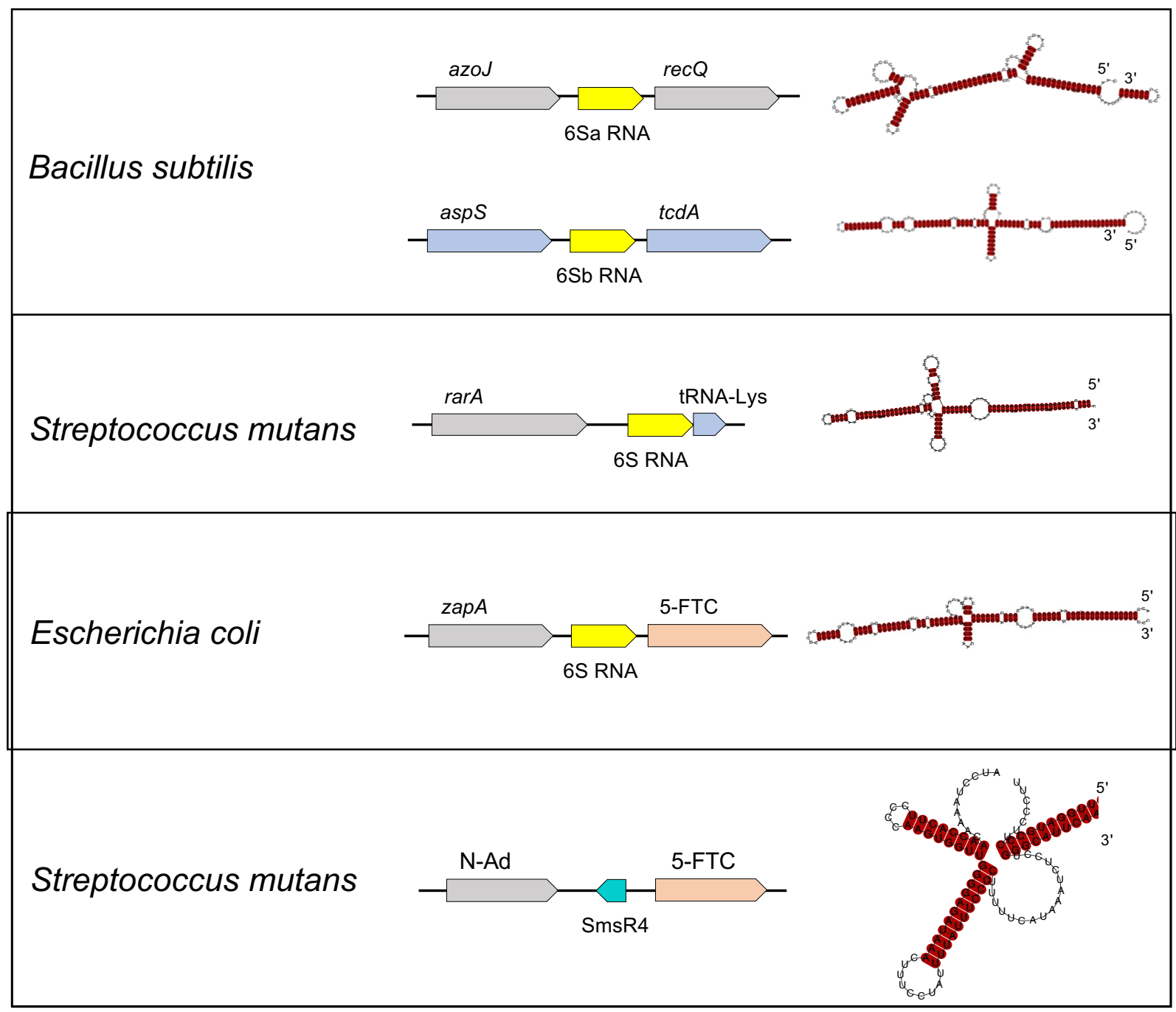


bioRxiv preprint doi: https://doi.org/10.1101/2021.11.16.468913; this version posted November 17, 2021. The copyright holder for this preprint (which was not certified by peer review) is the author/funder, who has granted bioRxiv a license to display the preprint in perpetuity. It is made available under aCC-BY-NC-ND 4.0 International license.
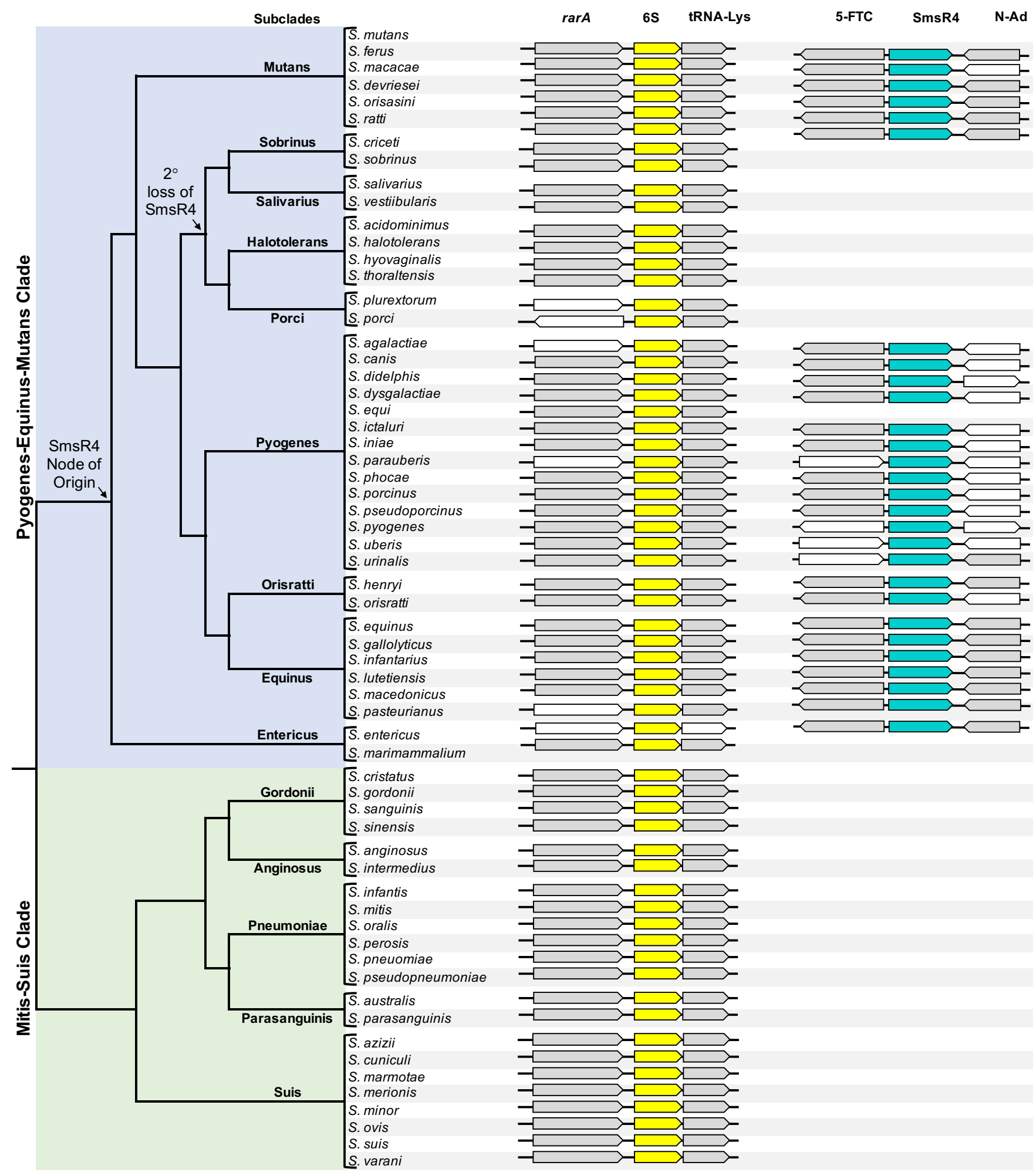


\section{BTR-G}

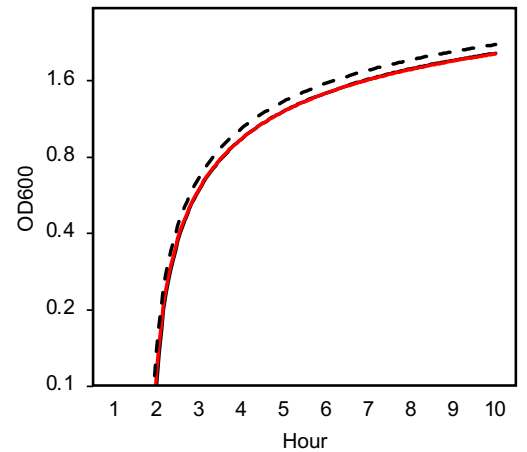

\section{BTR-S}

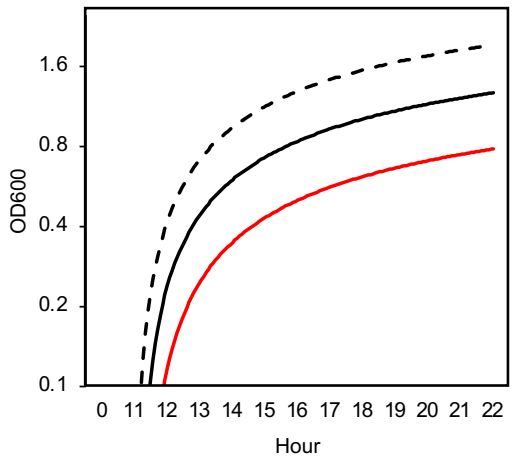

-WT - DEL -- COMP 


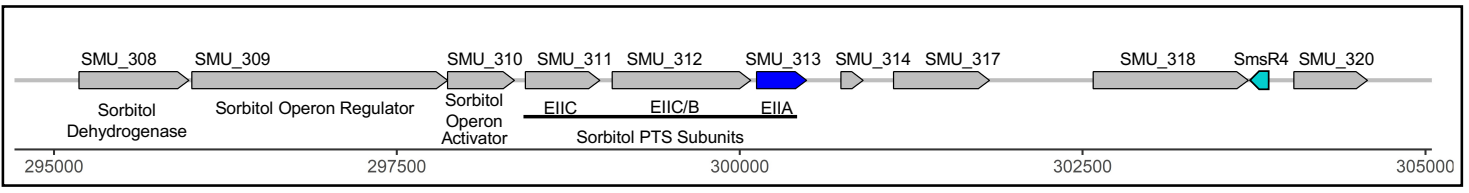




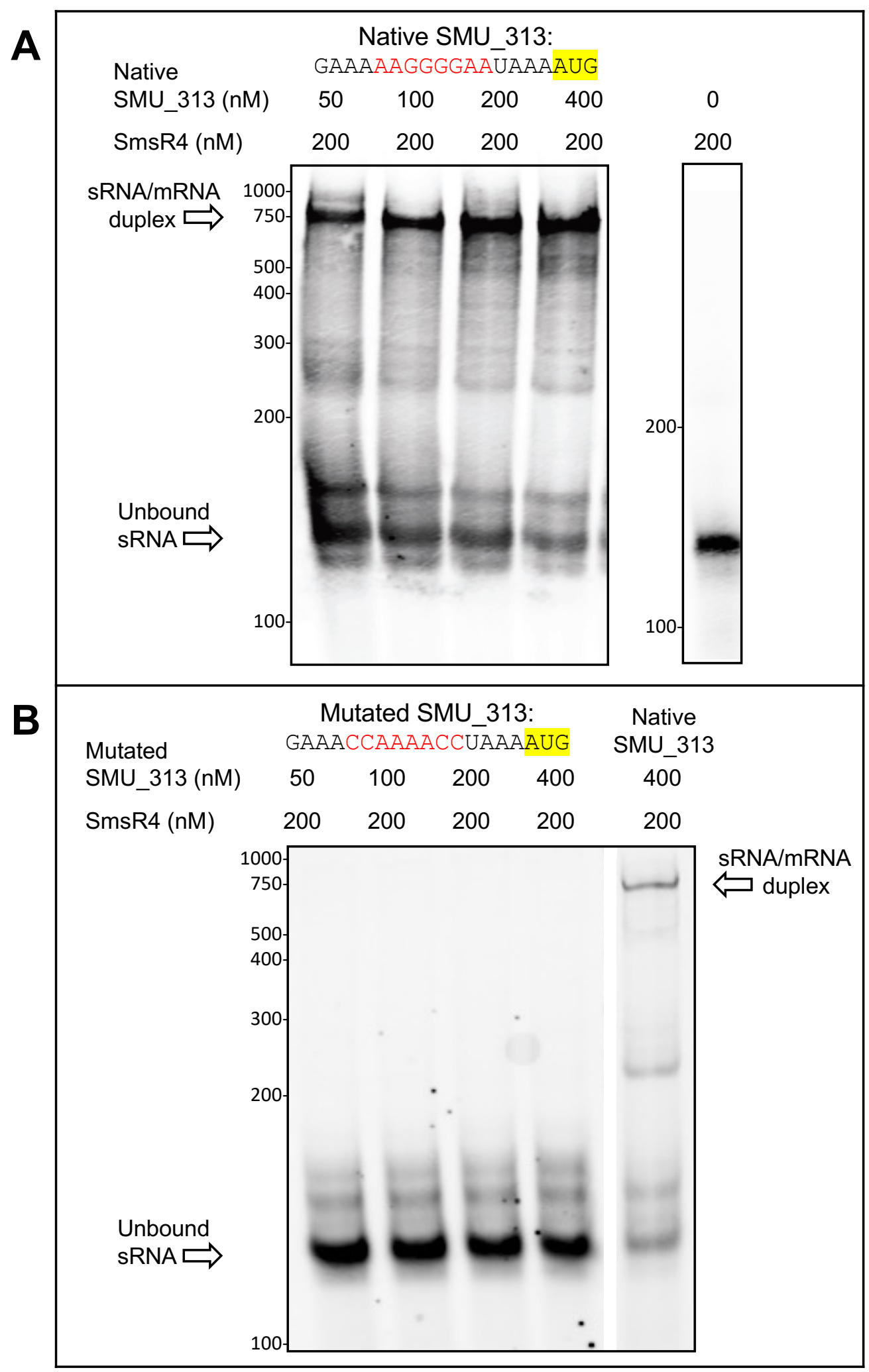

